\title{
BMJ Open Effect of mHealth tool on knowledge regarding reproductive health of school going adolescent girls: a before-after quasi-experimental study
}

\author{
Tanima Ahmed
}

To cite: Ahmed T. Effect of mHealth tool on knowledge regarding reproductive health of school going adolescent girls: a before-after quasiexperimental study. BMJ Open 2020;10:e036656. doi:10.1136/ bmjopen-2019-036656

- Prepublication history and additional materials for this paper is available online. To view these files, please visit the journal online (http://dx.doi. org/10.1136/bmjopen-2019036656).

Received 26 December 2019 Revised 14 September 2020 Accepted 22 September 2020

Deck for updates

(c) Author(s) (or their employer(s)) 2020. Re-use permitted under CC BY-NC. No commercial re-use. See rights and permissions. Published by BMJ.

Community Medicine, Uttara Adhunik Medical College, Dhaka, Bangladesh

Correspondence to

Dr Tanima Ahmed;

tanirif@gmail.com

\section{ABSTRACT}

Objective This study was executed to (1) assess the effect of mHealth (mobile health) tool on knowledge regarding reproductive health $(\mathrm{RH})$ of adolescent girls and (2) determine the utilisation of mHealth tool among school girls.

Design Before-after type of quasi-experimental study. Setting Dhaka North City Corporation in Bangladesh. Participants 400 adolescent girls aged $14-19$ years were selected based on defined criteria.

Interventions Short message service (SMS) intervention on $\mathrm{RH}$ was delivered through a mobile phone.

Primary and secondary outcome measures 8 schools out of 61 were randomly selected in the study area. A total of 400 girls were selected randomly on permission from those schools and parents. SMS interventions were delivered for 8 weeks. The data were collected using a self-administered questionnaire before and after SMS intervention to evaluate the effect. The number of responses to weekly SMS determined mHealth usage or practice.

Results Postintervention knowledge score (mean $70.8 \% \pm 9.7 \%$ ) on RH was significantly higher (paired $\mathrm{t}=69.721, \mathrm{p}<0.001$ ) than preintervention knowledge score (mean $44.71 \% \pm 9.13 \%$ ) with a large effect size (cohen's $d=3.6)$. The knowledge score on RH was $(p<0.001)$ correlated $(+0.636)$ with SMS response. Multiple linear regression indicated that increase response to one SMS intervention there was an increase of knowledge score by $2.661 \%$ (linear slope 2.66 , at $95 \% \mathrm{Cl}, \mathrm{p}<0.001$ ) after controlling the confounder. The mean knowledge score in all five knowledge segments of RH increased significantly $(p<0.001)$ after SMS intervention.

Conclusion The result indicated that the SMS tool of the mHealth approach is an easy and effective way to improve RH knowledge for adolescent girls. SMS intervention was well accepted by the girls. Thereby this mHealth tool can be chosen to provide health information for a mass approach.

\section{INTRODUCTION}

Technology is rapidly progressing in both developed and low-income and middleincome countries around the world. Indeed, it has the prospect to address issues ranging from basic education to primary healthcare.

\section{Strengths and limitations of this study}

- This is the first interventional study conducted in Bangladesh using the mobile health tool (short message service (SMS)) as an intermediary of health education on reproductive health $(\mathrm{RH})$ among adolescent girls.

- SMS intervention was also found well accepted among the girls and drop out was very low $(4.75 \%)$

- The study population was limited to adolescent school-going girls confined to schools of Dhaka North City Corporation in Bangladesh and did not include a separate control group to compare the effects.

- The intraclass correlation coefficient was very low, so a random sample approach was adopted for the analysis.

- The knowledge questionnaire and SMS contents were limited to a few topics of RH.

Mobile health (mHealth) is one form of information communication technology and is a subcategory of e-Health. This unique service is effective in disseminating standard and private health-related information. Since 1973, after the introduction of the first mobile phone by the DynaTAC, mobile devices (MDs) have developed as a significant component of mHealth. ${ }^{2}$

The WHO has defined mHealth as a 'medical and public health practice supported by MDs, such as mobile phones, patient monitoring devices, personal digital assistants (PDAs), and other wireless devices'. ${ }^{3}$ Further, other MDs such as smartphones, portable media players, tablet, personal computers have essential roles in mHealth. ${ }^{4}$ Different applications like short message service (SMS), online messages, calls, reminders and so on of these devices are being used to deliver health-related information as a part of mHealth service. Undeniably, mHealth has the potential to have a noticeable effect on 
the development of the healthcare sector, especially in the reproductive healthcare sector.

Bangladesh is a densely populated country with a population of over 62.7 million. ${ }^{5}$ In 2015, the Bangladesh Bureau of Statistics recorded that the adolescents account for $21 \%$ of the total population (around 33.8 million), which is increasing both in per cent and absolute count. ${ }^{6}$ Indeed, this growing part of the population will lead to the future progress of the country. Therefore, they need extra attention, as this vital period of their lives reflects their physical and psychological upbringing.

In 2010, a study about the reproductive health (RH) problems among adolescent girls identified that the majority of girls suffer from dysmenorrhoea, menorrhagia, oligomenorrhoea and other RH problems during early or throughout their reproductive periods. ${ }^{7}$ A health educational intervention study in 2014 further revealed that the girls face more complications during their periods, like menorrhagia, dysmenorrhoea, abdominal pain, nausea before the interventional programme. ${ }^{8}$ During menarche, most of the girls are scared, hesitate or shy to express their reproductive and menstrual health issues. Notably, the complex and conservative social and cultural context is a prime barrier during their early reproductive phase. A qualitative study in 2014 has also revealed that the conservative society of rural areas, community people, especially the parents and guardians, usually do not accept adolescent reproductive health (ARH) education being provided in the school. ${ }^{9}$

As a result, adolescents in Bangladesh are mostly either misinformed or poorly informed about the RH issues, predominantly throughout their reproductive years. Often the source of information is either their mother or friends who are equally uninformed. ${ }^{7810}$ Therefore, the availability of relevant RH related information or services along with limited access to it are the prime causes of such unawareness. Less information about essential services was identified as a discouraging factor of healthcareseeking behaviours among the adolescent girls in a study in 2018. ${ }^{11}$ United States Agency for International Develpoment (USAID's) situation analysis report in 2017 has also found that there is a lack of RH programme exclusively focused on adolescents in Bangladesh. The findings stated that the health facilities are only seen as 'family planning clinics'. It was also evident from the report that the adolescent sexual and reproductive health (ASRH) programme is unevenly distributed across the country which created a gap in sexual reproductive health (SRH) information and services for unmarried adolescents, especially for the girls. ${ }^{12}$

On a separate note, around 164.170 million people in Bangladesh are mobile phone subscribers. It was revealed by the Bangladesh Telecommunication Regulatory Commission in October 2019. ${ }^{13}$ Importantly, $45 \%$ of adolescents age between 15 and 19 years, and $8.8 \%$ of adolescents age between 13 and 14 years own a mobile phone. ${ }^{14}$ Therefore, mHealth could be a possible way to address the above issues and disseminate RH knowledge among adolescents.

Although adolescents have access to the mobile phone, however, literature shows that there is a minimal number of studies that provide information on mHealth service utilisation. Importantly, no cited literature was found regarding the effect of mHealth on RH knowledge among adolescents in Bangladesh. Undoubtedly, it is crucial to find out the effectiveness of mHealth service to disseminate ARH knowledge, especially for the girls. Therefore, the mHealth tool (SMS) was applied in this study.

The study aims to achieve primarily three goals. First, to identify the baseline knowledge on RH among schoolgoing adolescent girls. Second, to evaluate the effect of the mHealth tool. Finally, to determine the utilisation (response to SMS) of the mHealth tool among school girls.

\section{METHOD}

\section{Study design and settings}

A before-after quasi-experimental research design was used to evaluate the effectiveness of mHealth service in disseminating ARH knowledge. The study was conducted within the Dhaka North City Corporation (DNCC) area. DNCC is one of two municipal corporations, which governs 36 northern wards in Dhaka. The total area of this city corporation is $82.638 \mathrm{~km}^{2}$, with an approximate population of $395730215 .{ }^{15}$ A total of 52 secondary and higher secondary schools and 9 technical schools are located in DNCC as listed in the Bangladesh Bureau of Educational Information and Statistics (BANBEIS). ${ }^{16}$

To conduct this study, initially, 8 secondary and higher secondary schools and 2 technical schools were randomly selected from the BANBEIS list. However, among these 10 schools, only 3 secondary schools from Mirpur, Badda, Azimpur, 4 high schools from Uttara, Pallobi and Kafrul, and only 1 technical school from Mirpur allowed and permitted to conduct this study. Eventually, a total of eight schools were finally included in this study. Importantly, in Bangladesh, the secondary school level stands for the class or grade from 6 to 10 , and the higher secondary school level from class or grade 11 to 12 .

\section{Participants}

The precondition to participate in this study was to have access to a mobile phone. It could be either personal or access to any of the parent's mobile phone. Therefore, girls who met the prerequisite between the ages of 14 and 19 years were invited for the intervention process. Subsequently, among the prequalified girls, a random lottery was conducted using their unique school attendance registration number to select the final participants (figure 1). Incidentally, before the final selection process, formal consents from the participant's parents were also being taken through the school teachers.

\section{Sample size}

The sample size was estimated by using the formula, $n=z^{2} p q /$ $d^{2}$. Here, $n=$ desired sample size, $z=$ standard normal deviate 


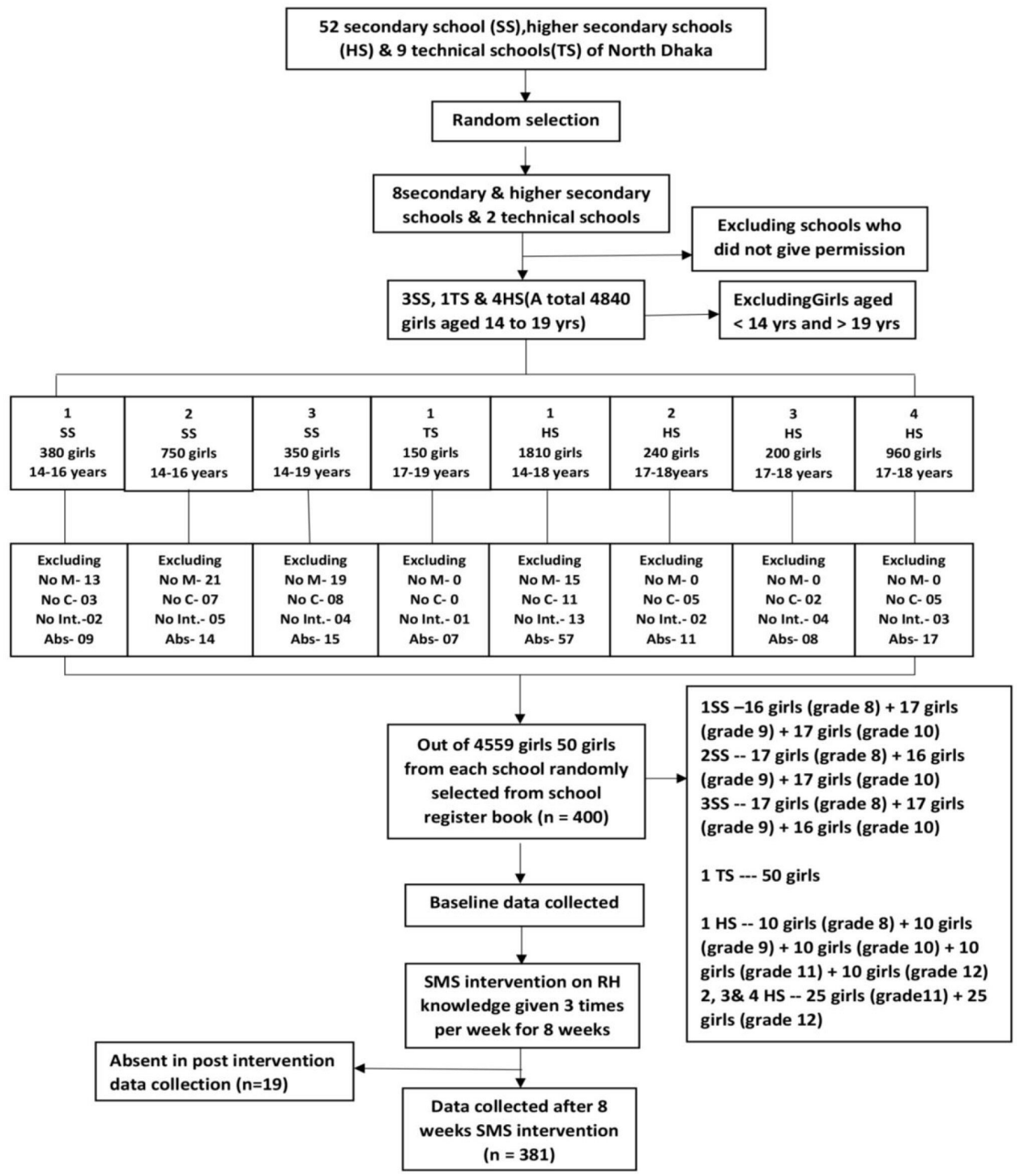

Figure 1 Participants engaging flow in intervention process. Abs, absent during predata collection; HS, higher secondary school; No C, no parent's consent; No Int, not interested; No M, no access to mobile; RH, reproductive health; SMS, short message service; SS, secondary school; TS, technical school.

set at 1.96 which corresponds to $95 \%$ CI, p=proportion of adolescent girls having knowledge on RH, $50 \%$ (assuming from the literature review), $\mathrm{q}=1-\mathrm{p}, \mathrm{d}=$ degree of freedom $5 \%$. Considering the available literature on RH knowledge among adolescent girls $(\mathrm{p}=0.5)$ provided a similar estimated sample size that was 384 . To avoid drop out, a total of 400 adolescent girls were included in this study.

\section{Data collection instruments}

The self-administered questionnaire comprised two parts. The first part included participant's sociodemographic data. The second part included a knowledge questionnaire on RH. The knowledge questionnaire has a total of 25 items under five segments (see online supplemental file). These segments are knowledge about the reproductive system, knowledge about adolescent health, knowledge about menstruation, knowledge of menstrual hygiene management (MHM) and knowledge about health issues related to $\mathrm{RH}$.
The items of the questionnaire and contents of SMS were designed by following the Adolescent Health related Training Guideline of Adolescent Health Programme, DGHS. The design of the SMS content was made following a study conducted in Ghana in $2017^{17} 18$ (see online supplemental file). An English questionnaire for data collection and SMS contents for intervention were developed initially. Afterwards, it was translated into Bengali following the textbook. A few minor modifications of some items were made based on pretesting of the questionnaire and SMS contents on 10 adolescent girls who were excluded during the main data collection.

\section{Data collection procedures}

The data for this study purpose was collected before and after the SMS intervention. Therefore, the participants from the respective schools filled out the questionnaire in the presence of their respective school teachers. Queries about the questionnaire were also being addressed and 
clarified on the spot. Written assents (for girl age below 18 ) and consents (for girls age 18 and above) were taken in advance from the participants. Moreover, the participants were allowed to withdraw from this study at any time without any recompense.

Importantly, the participants and their parents were also being assured about their privacy. Therefore, any sensitive information provided by the participants was kept confidential. Their name and any form of identification remained unpublished.

\section{Measuring knowledge}

Knowledge scores were calculated as the percentage of items answered correctly considering $60 \%$ score as cut-off value. The score was graded as, $<20 \%=$ very poor knowledge, 20\%-39\%=poor knowledge, $40 \%-59 \%=$ average knowledge, $60 \%-79 \%=$ good knowledge and $\geq 80 \%=$ very good knowledge. Any missing value or 'do not know' answers were treated as incorrect answers. After the SMS intervention participants were rewarded (a menstrual kit: a small pouch containing sanitary pad, wet wipes) for the highest score in the post-test.

\section{Process of SMS}

It was an interactive quiz. Each participant received a total of three SMS every week during the intervention period of 8 weeks. First SMS contained a multiple-choice quiz question on RH. The participants answered the quiz through a reply SMS. Afterwards, two SMS containing the correct answer along with additional information related to the quiz topic was sent sequentially. The respondent incurred no cost during this process.

\section{Measuring mHealth tool utilisation}

The responses received from the participants were collected from the mobile phone records. After concluding the 8 weeks of the intervention period, the total number of responses (maximum of 8 ) received was measured. As per the predefined measurement criteria, a cut-off of $70 \%$ responses were considered as a good response.

\section{Data analysis}

In this study, analysis were done considering the individual as a sample unit rather than cluster as the intraclass correlation coefficient was very small-0.013. Descriptive statistics were presented by frequency tables and diagrams. Inferential statistics were done using SPSS V.22 applying paired t-test to show the difference of knowledge score before and after the intervention, dividing the mean difference by SD to measure cohen's $d$ to get the effect size and multiple linear regression to determine the change in knowledge score on responses to SMS. The level of significance was set at $95 \%$ confidence level with $\mathrm{p}$ value $<5 \%$ for two tailed.

\section{Patient and public involvement}

This research was done without any public involvement. No participants were invited to comment on the study design and to consult to develop the study materials.

\section{RESULTS}

This study was conducted among 400 adolescent girls aged between 14 and 19 years. They received SMS intervention on RH knowledge for 8 weeks. Initially, the
Table 1 Distribution of respondent's age and mobile phone ownership

\begin{tabular}{|c|c|c|c|}
\hline $\begin{array}{l}\text { Age } \\
\text { (years) }\end{array}$ & Frequency & Per cent & $\begin{array}{l}\text { Mean } \pm S D \\
\text { (years) }\end{array}$ \\
\hline $14-15$ & 185 & 46.3 & $16.06 \pm 1.64$ \\
\hline $16-17$ & 112 & 28.0 & \\
\hline $18-19$ & 103 & 25.7 & \\
\hline Total & 400 & 100 & \\
\hline \multirow[t]{2}{*}{ Age group } & Mobile phon & & Total \\
\hline & Self & $\begin{array}{l}\text { Parents/sister/ } \\
\text { relatives/others }\end{array}$ & \\
\hline $\begin{array}{l}14-15 \\
\text { years }\end{array}$ & 58 (31.4\%) & $127(68.8 \%)$ & 185 (100\%) \\
\hline $\begin{array}{l}16-17 \\
\text { years }\end{array}$ & $69(61.6 \%)$ & 43 (38.4\%) & $112(28 \%)$ \\
\hline $\begin{array}{l}18-19 \\
\text { years }\end{array}$ & $61(59.2 \%)$ & $42(40.8 \%)$ & $103(25.75 \%)$ \\
\hline Total & $188(47 \%)$ & $212(53 \%)$ & 400 (100\%) \\
\hline
\end{tabular}

participants filled out a self-administered questionnaire before the SMS intervention period commenced. After 8 weeks, the second round of data were collected among the 381 participants using the same knowledge questionnaire. Notably, 19 participants were absent at the time of postintervention data collection.

These participants were further subcategorised under three groups based on their age ranging from 14 to 15 years, $16-17$ years and 18-19 years. The mean age of the respondents was $16.06 \pm 1.64$ years. About $47 \%$ of the respondents were using their own mobile phones. The rest of the $53 \%$ had access to a mobile phone of their parents or sisters or relatives or others (table 1 ).

The data analysis revealed that the mother, sister or friends are the primary source of RH information other than mHealth (around 74.3\%) followed by the textbook and the school teachers around $13.6 \%$ and $11.8 \%$ consecutively. In comparison, only $0.3 \%$ of the girls had received RH information from media (television/radio).

\section{Utilisation of mHealth (response to intervention)}

The mean SMS response was $6.24 \pm 1.33$. About $74.3 \%$ of students responded $\geq 6$ SMS, while $25.7 \%$ of students responded $<6$ SMS which was above the expected level (figure 2). Response to the SMS intervention showed an irregular fluctuating pattern over the 8 weeks. Response to SMS intervention was highest in first week $82.3 \%$, which reduced to $74 \%$ in third week. It again rose to $80 \%$ in fourth week and finally declined to $76.5 \%$ in the eighth week (figure 3).

\section{Knowledge score before and after the intervention}

Before SMS intervention mean knowledge score on RH was $44.71 \% \pm 9.13 \%$. Most of the respondents $(69.25 \%)$ scored average knowledge on $\mathrm{RH}, 27.0 \%$ had poor knowledge, and a few (only $3.75 \%$ ) had good knowledge. 


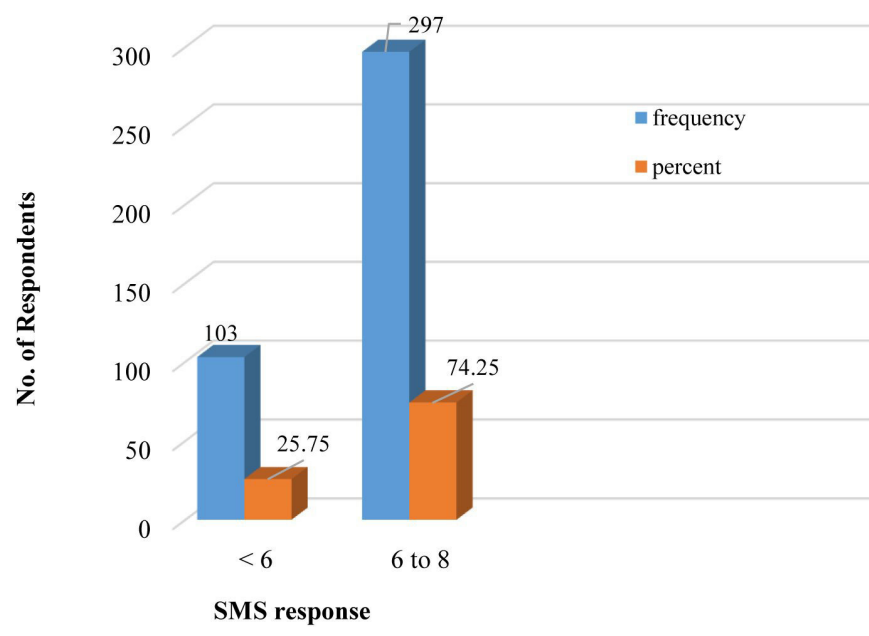

Figure 2 Distribution of short message service (SMS) response by the respondents.

Importantly, none of the participants scored very good knowledge. After the SMS intervention, a $4.8 \%$ sample was missing, and the mean knowledge score was $70.8 \% \pm 9.7 \%$. The majority of the students scored good knowledge $(67.72 \%)$, about $21.3 \%$ of students scored very good, and only $11.02 \%$ of students scored an average knowledge score. After SMS intervention, changes in the score of 5 different knowledge segment was also identified (table 2). Knowledge score difference before and after the SMS intervention was found significant (paired $\mathrm{t}=69.721, \mathrm{p}<0.001$ ) which was higher after the intervention, and the effect size cohen's $d=3.6$ indicated a very large effect (table 3).

\section{Relationship between SMS intervention and knowledge score} Correlation between SMS response and postintervention knowledge score was quite high, $\mathrm{R}=+0.636$, and highly significant $(p<0.001)$. The adjusted $R$ square value $(0.606)$ indicates that nearly $60.6 \%$ variance of knowledge score was explained by all the factors. Higher response to SMS was found associated with higher knowledge score (linear slope, estimate $2.661 \%$, 95\% CI 2.129

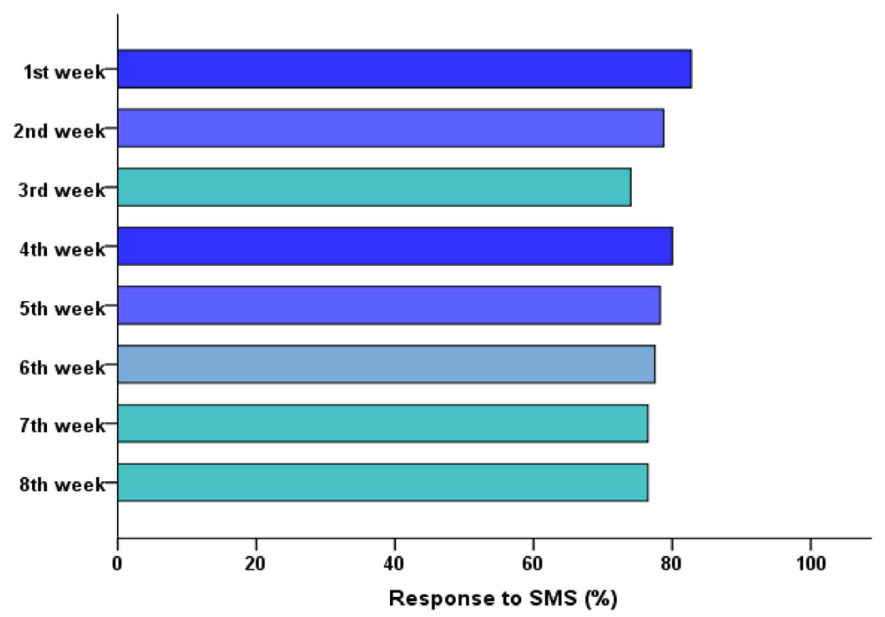

Figure 3 Participant's short message service (SMS) response by week.
Table 2 Distribution of knowledge score before $(n=400)$ and after $(n=381)$ short message service intervention

\begin{tabular}{|c|c|c|}
\hline Knowledge score (\%) & Before & After \\
\hline Poor $(20 \%-39 \%)$ & $108(27 \%)$ & $0(0 \%)$ \\
\hline Average $(40 \%-59 \%)$ & 277 (69.25\%) & $42(11.2 \%)$ \\
\hline Good (60\%-79\%) & $15(3.25 \%)$ & $258(67.72 \%)$ \\
\hline Very good ( $\geq 80 \%)$ & $0(0 \%)$ & $81(21.26 \%)$ \\
\hline Mean \pm SD (\%) & $44.71 \pm 9.13$ & $70.8 \pm 9.7$ \\
\hline Total & 400 & 381 (missing 19) \\
\hline \multicolumn{3}{|c|}{ Knowledge score in different segment of RH } \\
\hline Knowledge score (\%) & Before & After \\
\hline \multicolumn{3}{|l|}{ On reproductive system } \\
\hline Very poor (<20\%) & $107(26.75 \%)$ & $0(0 \%)$ \\
\hline Poor $(20 \%-39 \%)$ & $293(73.25 \%)$ & $165(43.3 \%)$ \\
\hline Average (40\%-59\%) & $0(0 \%)$ & $151(39.6 \%)$ \\
\hline Good (60\%-79\%) & $0(0 \%)$ & $37(9.7 \%)$ \\
\hline Very good $(\geq 80 \%)$ & $0(0 \%)$ & $28(7.3 \%)$ \\
\hline Mean \pm SD & $28.87 \pm 7.38$ & $47.6 \pm 15.4$ \\
\hline \multicolumn{3}{|l|}{ On adolescent health } \\
\hline Poor (20\%-39\%) & $1(0.25 \%)$ & $0(0 \%)$ \\
\hline Average (40\%-59\%) & $51(12.75 \%)$ & $0(0 \%)$ \\
\hline Good (60\%-79\%) & $221(55.25 \%)$ & $16(4.2 \%)$ \\
\hline Very good ( $\geq 80 \%)$ & 127 (31.75\%) & $365(95.8 \%)$ \\
\hline Mean $\pm S D$ & $79.63 \pm 16.24$ & $99.01 \pm 4.9$ \\
\hline \multicolumn{3}{|l|}{ On menstruation } \\
\hline Very poor $(<20 \%)$ & $27(6.75 \%)$ & $0(0 \%)$ \\
\hline Poor (20\%-39\%) & $180(45 \%)$ & $0(0 \%)$ \\
\hline Average (40\%-59\%) & $185(46.25 \%)$ & $61(16 \%)$ \\
\hline Good (60\%-79\%) & $7(1.75 \%)$ & $133(34.9 \%)$ \\
\hline Very good $(\geq 80 \%)$ & $1(0.25 \%)$ & $187(49.1 \%)$ \\
\hline Mean \pm SD & $40.62 \pm 10.96$ & $72.6 \pm 12.6$ \\
\hline \multicolumn{3}{|l|}{ On MHM } \\
\hline Poor (20\%-39\%) & $6(1.5 \%)$ & $0(0 \%)$ \\
\hline Average (40\%-59\%) & $143(35.75 \%)$ & $0(0 \% 0$ \\
\hline Good (60\%-79\%) & $182(45.5 \%)$ & $27(7.1 \%)$ \\
\hline Very good ( $\geq 80 \%)$ & $69(17.25 \%)$ & $354(92.9 \%)$ \\
\hline Mean \pm SD & $69.62 \pm 18.5$ & $98.23 \pm 6.4$ \\
\hline \multicolumn{3}{|l|}{ On RH problem } \\
\hline Poor (20\%-39\%) & $385(96.25 \%)$ & $41(10.8 \%)$ \\
\hline Average $(40 \%-59 \%)$ & $15(3.75 \%)$ & $124(32.5 \%)$ \\
\hline Good (60\%-79\%) & $0(0 \%)$ & $168(44.1 \%)$ \\
\hline Very good ( $\geq 80 \%)$ & $0(0 \%)$ & $48(12.6 \%)$ \\
\hline Mean $\pm S D$ & $20.75 \pm 3.8$ & $51.71 \pm 16.9$ \\
\hline Total & 400 & 381 \\
\hline
\end{tabular}

MHM, menstrual hygiene management; $\mathrm{RH}$, reproductive health.

to 3.193) after adjustment of other covariates (knowledge from teachers, books and preintervention) which was also statistically significantly $(\mathrm{t}=9.832, \mathrm{p}<0.001)$. It indicated that the increase of one SMS response resulted in an increase in knowledge by $2.661 \%$ when other factors remained constant (table 4 ). 
Table 3 Relation between mean knowledge score before and after short message service intervention

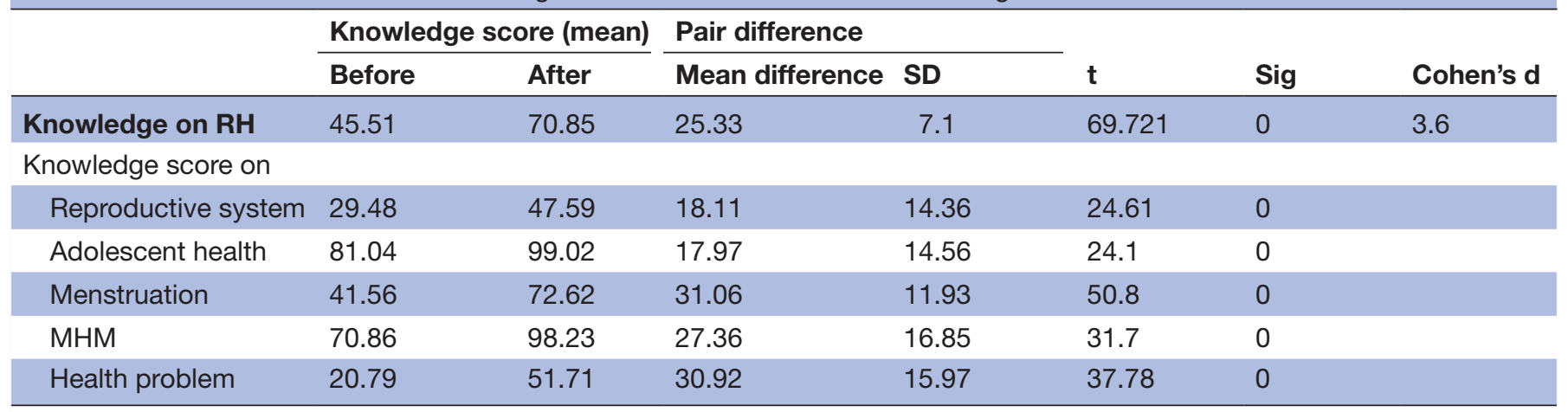

MHM, menstrual hygiene management; $\mathrm{RH}$, reproductive health.

\section{DISCUSSION}

The study has identified several findings to measure the effectiveness of the mHealth tool. The number and frequencies of responses, the RH knowledge score before and after the intervention followed by the preintervention and postintervention mean difference of RH knowledge score, the outcome of SMS intervention on RH knowledge score, to name a few. Importantly, some of the findings resemble previous studies conducted in similar and related areas.

Overall, the responses to the SMS intervention of this study were satisfactory. On average, $6.24 \pm 1.33$ SMS were responded by the participants. Around $74.3 \%$ of participants, among 400 adolescent school-going girls responded to $\geq 6$ SMS intervention. It resemblances with another study conducted in Ghana in 2017. In that study, the average number of responses was 8 out of 12 SMS, and around $81 \%$ of the respondents were engaged in the mHealth intervention programme. ${ }^{17}$ On the other hand, the response to SMS intervention in this study showed an irregular fluctuating pattern. It was the highest in the first week of the study, which declined in the third week. A possible reason for the decline could be the mid-term examinations in some of the schools. Afterwards, the responses started to peak but then dropped again in the last weeks.

The mean score of baseline knowledge on RH was $44.71 \% \pm 9.13 \%$, which was not satisfactory. This score has also implied similar conclusions of a couple of previous studies. In 2014, a qualitative study about student's RH knowledge, perceptions and behaviour identified that there was a lack of knowledge on RH among adolescent girls. ${ }^{9}$ In that same

Table 4 Relationship between short message service (SMS) utilisation (response) and postintervention knowledge score

\begin{tabular}{lllrl}
\hline Factors & $\mathbf{R}$ & Adj $\mathbf{R}^{2}$ & $\mathbf{t}$ & Sig \\
\hline (Constant) & & & 14.474 & 0 \\
Total SMS response & 0.636 & 0.403 & 9.832 & 0 \\
Teacher & 0.636 & 0.402 & -1.897 & 0.059 \\
Book & 0.655 & 0.424 & 1.304 & 0.193 \\
Pretest knowledge & 0.781 & 0.606 & 13.229 & 0 \\
\hline
\end{tabular}

year, another school-based intervention study on menstrual knowledge revealed that the baseline knowledge was about $51 \%$ among the participants. ${ }^{8}$

The further analysis of the data revealed a strong indication of the level of knowledge on the reproductive system among adolescents. The majority of the respondents in this study have poor knowledge (around $73.25 \%$ ), whereas $26.75 \%$ of the participants have very poor knowledge. On the other hand, a study in Menstrual Hygiene Condition of Adolescent Schoolgirls at Chittagong Division in Bangladesh revealed that almost $25.5 \%$ of respondents had no clear idea about the reproductive system and its function. ${ }^{19}$ Importantly, that particular finding in 2013 is still very much relatable with this study conducted in 2019 in a different region of Bangladesh. Besides, as for knowledge on menstruation, around $45 \%$ of girls in this study have poor knowledge while only a few students $(0.25 \%)$ have very good knowledge. A study conducted on MHM knowledge found that $49 \%$ of the girls had no idea about menstruation, which is again similar to this study. $^{20}$

On the query to MHM, more than one-third of the respondents $(35.75 \%)$ in this study have scored average knowledge, although the rest have scored good knowledge. However, the majority of the girls $(96.25 \%)$ have poor knowledge of $\mathrm{RH}$ problems. Unlike this finding, a study on menstrual hygiene among the students of non-government secondary schools in 2014 revealed a different outcome. It found that $33.1 \%$ of the participants were unaware of the use of hygienic materials during menstruation. ${ }^{10}$ Further, around $64.6 \%$ of the participants were unaware of the complications due to unhygienic practice during menstruation. ${ }^{10} \mathrm{~A}$ variance in sociodemographics among the participants in both the studies perhaps could be the primary cause of discrepancies.

Further analysis of this effect of the mHealth tool study revealed that the knowledge score was increased to $70.8 \% \pm 9.7 \%$ after the 8 weeks SMS intervention on $\mathrm{RH}$ knowledge. Indeed, it is a very satisfactory outcome. A study conducted in Malaysia in 2013 had similar findings. The SMS intervention on SRH knowledge had improved the knowledge score $(15.90, \mathrm{SD} \pm 3.321)$ among girls on that study. ${ }^{19}$ Importantly, the Mean difference of the RH knowledge score was significantly higher ( paired $\mathrm{t}=69.721$, 
$\mathrm{p}<0.001)$ after SMS intervention in this study. The mean knowledge score in different knowledge segment of RH was also increased significantly $(\mathrm{p}<0.001)$ after the intervention. The two other similar types of studies conducted in Malaysia and Ghana have further supported these findings. The Effects of Short Health Messages Intervention in improving the SRH knowledge study in Malaysia found a significant $(p<0.034)$ difference in knowledge score before and after the mHealth intervention. ${ }^{21}$ Furthermore, in 2017 Ghana found that the mHealth programme was effective in increasing knowledge significantly for every subgroup at 3 months interval. ${ }^{17}$

Above all, the knowledge score of this study after the intervention was positively correlated $(+0.636)$ with SMS responses $(p<0.001)$, which is a remarkable outcome. Multiple linear regression indicated that for an increase of one SMS response, there was an increase in knowledge by $2.661 \%$ after controlling other factors (linear slope estimate $2.661,95 \%$ CI 2.129 to 3.193 ). Referring to the Malaysian study in 2017, a higher level of engagement in SMS intervention was associated with higher knowledge scores (linear slope estimate $0.11,95 \%$ CI 0.08 to 0.14 ) at 3 months interval. ${ }^{17} \mathrm{~A}$ literature review on the impact of mHealth on ASRH also concluded that the mHealth based interventions had positive effects on improving knowledge. ${ }^{22}$ That analysis was based on the secondary data collected from published literature.

Additionally, around $47 \%$ of respondents of this study were using their personal mobile phones while the rest of the participants $(53 \%)$ had access to a mobile phone owned by their parents, sisters, relatives or others. In 2014, Bangladesh Demographic and Health Survey (BDHS's) report stated that $45 \%$ of adolescents between 15 and 19 years have their personal mobile phone. ${ }^{23}$ Whereas, the percentage declined significantly among adolescents between 13 and 14 years (around 8.8\%). ${ }^{23}$ BDHS's report reinforces the findings of this study.

Indeed, this study has revealed and reinforced several crucial findings within its limited scope. Even so, the following limitations need to consider: first, this study was designed to identify the effect of SMS intervention on RH knowledge. Therefore, the practice of this knowledge and the persistence of gained knowledge are out of the scope. Moreover, the population of this study was limited to adolescent girls in North Dhaka city in Bangladesh. Hence, it may not fully represent the entire adolescent population of the country. Notably, the methodology of this study was a one-group before after quasiexperimental research. Therefore, involving any separate control group was out of the scope. Any change in knowledge score was calculated by comparing the before and after effects of SMS intervention. It was measured in the same group. Though the sample was selected randomly by two steps and it naturally developed as clusters but cluster analysis was avoided. As the intraclass correlation coefficient was very poor $(-0.013)$, which means the variability within school exceeds the variability between the schools, which means if two members chosen randomly from any school vary almost as much as any two randomly chosen members of the whole population. So individual was counted as a sample unit rather than cluster and a random sample approach was adopted. Besides, the knowledge questionnaire was confined to limited topics of $\mathrm{RH}$ as the intervention process was carried out only for 8 weeks. Finally, though all plausible steps were taken to make the SMS intervention effective. However, other environmental factors may likely to affect the results. For example, girls who had to access their parent's mobile perhaps missed responding in due time.

Adolescents in Bangladesh, mostly girls, are shy and hesitate to talk or discuss RH. The primary cause, as previously identified, is the barrier of conservative social and cultural context. By considering this, the study has revealed several crucial findings and concluded on the effects of the mHealth tool. Indeed, policymakers can use these findings to enhance access to RH knowledge for adolescents in Bangladesh.

\section{CONCLUSION AND RECOMMENDATIONS}

Adolescents in Bangladesh are mostly unaware, misinformed or poorly informed about RH issues. They have insufficiency in knowledge and are likely to face major RH problems. This study has accomplished its objectives and concluded on the effectiveness of mHealth service to disseminate ARH knowledge. The results suggested that the mHealth service has the potential to involve adolescent girls and improve their RH knowledge. SMS intervention, as an mHealth tool (health SMS) on RH knowledge, was well accepted by the participants, increased their knowledge scores and sustained even after 2 months (8 weeks) of the intervention. Undeniably, adequate knowledge of $\mathrm{RH}$ among the girls is essential to prevent any undesirable consequences. Therefore, the mHealth tool perhaps the next promising medium to disseminate health information for a mass approach. As the clustering in this study had poor reliability, a further study with a precise sampling technique and multiple approaches of mHealth is highly recommended.

Acknowledgements The author would like to acknowledge and thank the school authorities who gave permission to conduct the study in their schools, the teachers for giving assistance during the data collection, the adolescents involved in the intervention process and the expert reviewers for questionnaire validation and intervention tool development.

Contributors TA developed the proposal and implemented the study following data collection, analysis and writing the manuscript.

Funding The author has not declared a specific grant for this research from any funding agency in the public, commercial or not-for-profit sectors.

Competing interests None declared.

Patient consent for publication Not required.

Ethics approval Institutional Review Board (IRB) of National Institute of Preventive and Social Medicine approved this study.

Provenance and peer review Not commissioned; externally peer reviewed.

Data availability statement Data are available upon reasonable request. The data sets used and/or analysed in this study are available from the corresponding author on reasonable request. 
Supplemental material This content has been supplied by the author(s). It has not been vetted by BMJ Publishing Group Limited (BMJ) and may not have been peer-reviewed. Any opinions or recommendations discussed are solely those of the author(s) and are not endorsed by BMJ. BMJ disclaims all liability and responsibility arising from any reliance placed on the content. Where the content includes any translated material, BMJ does not warrant the accuracy and reliability of the translations (including but not limited to local regulations, clinical guidelines, terminology, drug names and drug dosages), and is not responsible for any error and/or omissions arising from translation and adaptation or otherwise.

Open access This is an open access article distributed in accordance with the Creative Commons Attribution Non Commercial (CC BY-NC 4.0) license, which permits others to distribute, remix, adapt, build upon this work non-commercially, and license their derivative works on different terms, provided the original work is properly cited, appropriate credit is given, any changes made indicated, and the use is non-commercial. See: http://creativecommons.org/licenses/by-nc/4.0/.

\section{ORCID iD}

Tanima Ahmed http://orcid.org/0000-0001-6161-8806

\section{REFERENCES}

1 Akter S, Ray P. mHealth - an ultimate platform to serve the unserved. Yearb Med Inform 2010;19:94-100.

2 Istepanian R, Jovanov E, Zhang YT. Introduction to the special section on M-Health: beyond seamless mobility and global wireless health-care connectivity. IEEE Trans Inf Technol Biomed 2004;8:405-14.

3 WHO. mHealth new horizons for health through mobile technologies: global observatory for eHealth. Geneva: WHO, 2011.

4 Free C, Phillips G, Galli L, et al. The effectiveness of mobile-health technology-based health behaviour change or disease management interventions for health care consumers: a systematic review. PLoS Med 2013;10:e1001362.

5 Bangladesh Bureau of Statistics. Bangladesh statistics, 2018. Available: http://bbs.portal.gov.bd/sites/default/files/files/bbs.portal. gov.bd/page/a1d32f13_8553_44f1_92e6_8ff80a4ff82e/Bangladesh\% 20\%20Statistics-2018.pdf

6 Bangladesh Bureau of Statistics. Bangladesh statistics, 2017. Available: http://bbs.portal.gov.bd/sites/default/files/files/bbs.portal. gov.bd/page/a1d32f13_8553_44f1_92e6_8ff80a4ff82e/Bangladesh\% 20\%20Statistics-2017.pdf [Accessed Dec 2018].

7 Afrin S, Rahman MR, Rahman M, et al. Reproductive health problems among the adolescent girls. Bangladesh Med J 2010;39:22-5.

8 Haque SE, Rahman M, Itsuko K, et al. The effect of a school-based educational intervention on menstrual health: an intervention study among adolescent girls in Bangladesh. BMJ Open 2014;4:e004607.
9 Aktar B, Sarkar M, Jenkins J. Exploring adolescent reproductive health knowledge, perceptions, and behavior, among students of Non-Government secondary schools supported by brac mentoring program in rural Bangladesh. Journal of Asian Midwives 2014;1:17-33.

10 Akther N, Begum N, Chowdhury S, et al. Knowledge on reproductive health issues among the unmarried adolescent girls. J Family Rep Health 2012;6:169-76.

11 Alam SS, Rahman MN, Mia MA, et al. Reproductive health status and health seeking behavior of adolescent girls in selected urban slum of Dhaka City in Bangladesh. Glob J Reprod Med 2018;5.

12 Ainul S, Bajracharya A, Reichenbach L, et al. Adolescents in Bangladesh: a situation analysis of programmatic approaches to sexual and reproductive health education and services. USAIDs. The Evidence Project 2017.

13 BTRC. Mobile phone subscribers in Bangladesh, 2019. Available: http://www.btrc.gov.bd/content/mobile-phone-subscribersbangladesh-october-2019 [Accessed Nov 2019].

14 BDHS. Bangladesh demographic and health survey, 2014. Available: https://dhsprogram.com/pubs/pdf/FR311/FR311.pdf [Accessed Nov 2018].

15 DNCC. Dhaka North City Corporation. Available: www.dncc.gov.bd [Accessed Dec 2018].

16 BANBEIS. Bangladesh Bureau of educational information and statistics, 2017. Available: http://www.banbeis.gov.bd/ [Accessed Dec 2018].

17 Rokicki S, Fink G. Assessing the reach and effectiveness of mHealth: evidence from a reproductive health program for adolescent girls in Ghana. BMC Public Health 2017;17:969.

18 Rokicki S, Cohen J, Salomon JA, et al. Impact of a Text-Messaging program on adolescent reproductive health: a cluster-randomized trial in Ghana. Am J Public Health 2017;107:298-305.

19 Muhit IB, Chowdhury ST. Menstrual hygiene condition of adolescent schoolgirls at Chittagong division in Bangladesh. Int J Sci Tech Res 2013;2:58-62.

20 Alam M-U, Luby SP, Halder AK, et al. Menstrual hygiene management among Bangladeshi adolescent schoolgirls and risk factors affecting school absence: results from a cross-sectional survey. BMJ Open 2017;7:e015508.

21 Ujang F, Sutan R. The effects of short health messages intervention in improving knowledge and attitude on sexual and reproductive health among late adolescents at colleges in Malaysia. Open J Prev Med 2018;08:207-28.

22 Ihesie CA. Is mobile health (mHealth) the magic bullet? a short review of the impact of mHealth on adolescent sexual health. Journal of Public Health and Epidemiology 2015;7:258-62.

23 NIPORT. Mitra and associates, and ICF Int. Bangladesh demographic and health survey 2014. Dhaka, Bangladesh, and Rockville, Maryland, USA: NIPORT, Mitra and associates, and ICF international, 2016. Available: https://dhsprogram.com/pubs/pdf/FR311/FR311.pdf 